\title{
Searching for Beta-Haemolysin hlb Gene in Staphylococcus pseudintermedius with Species-Specific Primers
}

\author{
Wioletta Kmieciak $^{1} \cdot$ Eligia M. Szewczyk ${ }^{1} \cdot$ Marcin Ciszewski $^{1}$
}

Received: 5 October 2015/Accepted: 3 March 2016/Published online: 16 April 2016

(c) The Author(s) 2016. This article is published with open access at Springerlink.com

\begin{abstract}
The paper presents an analysis of 51 Staphylococcus pseudintermedius clinically isolated strains from humans and from animals. Staphylococcus pseudintermedius strains' ability to produce $\beta$-haemolysin was evaluated with phenotypic methods (hot-cold effect, reverse CAMP test). In order to determine the $h l b$ gene presence (coding for $\beta$-haemolysin) in a genomic DNA, PCR reactions were conducted with two different pairs of primers: one described in the literature for Staphylococcus aureus and recommended for analysing SIG group staphylococci and newly designed one in CLC Main Workbench software. Only reactions with newly designed primers resulted in product amplification, the presence of which was fully compatible with the results of phenotypic $\beta$-haemolysin test. Negative results for $S$. aureus and $S$. intermedius reference ATCC strains suggest that after further analysis the fragment of $h l b$ gene amplified with primers described in this study might be included in the process of $S$. pseudintermedius strains identification.
\end{abstract}

\section{Introduction}

Staphylococcus pseudintermedius belongs to the coagulasepositive staphylococci and together with Staphylococcus intermedius and Staphylococcus delphini constitutes SIG group ("Staphylococcus intermedius group"). S. pseudintermedius

Marcin Ciszewski

marcin.ciszewski@umed.lodz.pl

1 Department of Pharmaceutical Microbiology and Microbiological Diagnostics, Medical University of Łódź, 137 Pomorska St., 90-235 Lodz, Poland colonizes skin and mucosal membranes of animals, notably dogs and cats, and constitutes their opportunistic pathogen [5]. This species is prevalent in a veterinary hospital environment $[15,25,32]$, which might be connected with the fact that people having frequent contact with animals (especially pets' owners or veterinary personnel) usually become carriers of this species of bacteria $[1,13,18,19]$. Human infections due to $S$. pseudintermedius occur usually in immunocompromised patients; however, their frequency has been still increasing [29, 31]. Infections in humans, such as catheter-borne bacteremia [3], sinusitis [27], infective endocarditis [20], non-hospital pneumonia [17] and wound infection after bone marrow transplantation [23] have already been noted. Further increase in the number of infections is highly possible, due to the fact that S. pseudintermedius is well equipped with various virulence factors i.e. coagulase, protease, enterotoxins, SIET exfoliative toxin, Luk-I leukotoxin and haemolysins (mainly $\beta$, but some strains also $\delta$ and $\alpha)[2,8,11]$.

The haemolysin type that has been most precisely described in the literature is staphylococcal $\beta$-haemolysin produced by Staphylococcus aureus and it constitutes a benchmark to haemolysin studies in other species [7]. In $S$. pseudintermedius, similarly to $S$. intermedius, $\beta$-haemoly$\sin$ is considered to be produced constitutively [24]. $\beta$-haemolysin (sphingomyelinase) has a unique mechanism of action, such that it hydrolyses one of cell membrane lipids (sphingomyelin) to ceramides and phosphorylcholine, leading to cell lysis due to cell membrane destabilization [16]. Additionally, it stimulates the process of biofilm formation in vivo [14], exhibits cytolytic activity against human monocytes and macrophages [30], and it inhibits chemotaxis [28].

The activity of $\beta$-haemolysin is usually tested using sheep erythrocytes due to significant amount of 
sphingomyelin in their cytoplasmic membranes. The haemolytic effect is reinforced by lowering the incubation temperature, which prompts the characteristic hot-cold effect [26]. Co-haemolysis in reverse CAMP test and other CAMP-like tests is another method to test for the presence of $\beta$-haemolysin [21]. Molecular analyses detecting $h l b$ gene, coding for $\beta$-haemolysin are becoming also more and more frequently used $[10,11]$.

\section{Methods}

\section{Bacterial Strains}

51 clinical strains of Staphylococcus pseudintermedius (13 obtained from humans and 38 from animals, mainly from dogs) were analysed, as well as 6 clinical strains of Staphylococcus epidermidis isolated from humans used as a negative control (this species does not produce $\beta$-haemolysin). All the tested strains were obtained from hospital and veterinary laboratories in Lodz, Poland. Strains were identified with MALDI-TOF system (Matrix-Assisted Laser Desorption/Ionization-Time of Flight Analysis) [4] and with genotypic method previously described by Sasaki et al. [22]. Staphylococcus aureus ATCC $^{\circledR} 25923$ and S. intermedius ATCC $^{\circledR} 29663$ reference strains were obtained from ATCC (LGC Standards) collection.

\section{Hot-Cold Effect}

Analysed strains were incubated on a $5 \%$ sheep blood agar at $37{ }^{\circ} \mathrm{C}$ for $24 \mathrm{~h}$. Afterwards, the haemolysis effect was tested for. Subsequently, they were incubated at $4{ }^{\circ} \mathrm{C}$ for the next $16 \mathrm{~h}$ and analysed again. The enlargement of haemolysis zone around bacterial colonies after incubation at $4{ }^{\circ} \mathrm{C}$ ("double" haemolysis) was considered as a positive result.

\section{Reverse CAMP Test}

In the middle of the $5 \%$ sheep blood agar, reference strain of Streptococcus agalactiae (producing CAMP factor) was inoculated. Analysed strains were inoculated perpendicularly to the reference strain. Afterwards, the culture was incubated in $37{ }^{\circ} \mathrm{C}$ for $24 \mathrm{~h}$. An enlarged haemolysis zone near the reference $S$. agalactiae strain ("arrowhead") was considered as a positive result.

\section{DNA Isolation}

Genomic DNA isolation was performed from overnight bacterial culture according to Genomic Mini AX BACTERIA SPIN (A\&A Biotechnology) protocol.

\section{PCR Reactions}

In order to determine the $h l b$ gene presence in genomic DNA, PCR reactions were conducted with 2 different pairs of primers: one recommended in the literature [11] and another one, which was newly designed in the CLC Main Workbench 7.6 (QIAGEN) software, basing on S. pseudintermedius ED99 complete genome deposited in Genbank (NC_017568.1). PCR reaction temperature profile was as follows: initial denaturation $2: 30 \mathrm{~min} .-94{ }^{\circ} \mathrm{C}, 30$ cycles (denaturation $0: 30 \mathrm{~min} . \quad-94{ }^{\circ} \mathrm{C}$, annealing 0:30 min. $-56{ }^{\circ} \mathrm{C}$, elongation $1: 00 \mathrm{~min} .-72{ }^{\circ} \mathrm{C}$ ) and final elongation 10:00 min. $-72{ }^{\circ} \mathrm{C}$. Primer sequences and expected amplicon sizes are presented in Table 1 .

\section{Agarose Gel Electrophoresis}

PCR products were separated during electrophoresis in $1 \%$ agarose gel (TAE buffer, $70 \mathrm{~V}, 60 \mathrm{~min}$.).

\section{Statistical Analysis}

Statistical analysis was performed using STATISTICA 10 software (Statsoft).

\section{Results}

The results of phenotypic and genotypic analyses for $S$. pseudintermedius strains are shown in Table 2.

$\beta$-haemolysin was phenotypically detected (hot-cold effect and reverse CAMP test) in $61 \%$ of analysed $S$. pseudintermedius and none of $S$. epidermidis negative control strains. One of $S$. pseudintermedius strains did not produce $\beta$-haemolysin. In $35 \%$ of $S$. pseudintermedius strains, $\beta$-haemolysin production was detected only by hot-
Table 1 Primers used in this study

\begin{tabular}{llc}
\hline Primers for $h l b$ gene & Sequence & Amplicon size \\
\hline Described in the literature [11] & 5'-GTGCACTTACTGACAATAGTGC-3' $^{\prime} 309 \mathrm{bp}$ \\
& 5'-GTTGATGAGTAGCTACCTTCAGT-3' $^{\prime}$ & \\
Newly designed & 5'-GACGAAAATCAAGCGGAA-3' $^{\prime}$ & $734 \mathrm{bp}$ \\
& 5'-TCTAAATACTCTGGCGCAC-3' $^{\prime}$ & \\
\hline
\end{tabular}


Table 2 The results of phenotypic and genotypic tests for S. pseudintermedius strains, evaluating the ability to produce $\beta$-haemolysin and the presence of $h l b$ gene

\begin{tabular}{|c|c|c|c|c|}
\hline Strains & $\begin{array}{l}\text { Hot-cold } \\
\text { effect }\end{array}$ & $\begin{array}{l}\text { Reverse } \\
\text { CAMP }\end{array}$ & $\begin{array}{l}\text { hlb (literature } \\
\text { primers) }\end{array}$ & $\begin{array}{l}\text { hlb (new } \\
\text { primers) }\end{array}$ \\
\hline SPI 188, SPI 237 & + & + & + & + \\
\hline $\begin{array}{l}\text { SPI } 150 \text {, SPI } 187, \text { SPI } 197, \text { SPI } 211, \text { SPI } 215 \text {, SPI } 216, \text { SPI } 222, \text { SPI } 227, \text { SPI } 228, \text { SPI } \\
\text { 230, SPI 273, SPI 286, SPI 305, SPI 324, SPI 378, SPI 391, SPI 397, SPI 398, SPI 399, } \\
\text { SPI 404, SPI 418, SPI 434, SPI 442, SPI 526, SPI 639, SPI 671, SPI 699, SPI 796, SPI- } \\
\text { X3 }\end{array}$ & + & + & - & + \\
\hline $\begin{array}{l}\text { SPI } 185 \text {, SPI } 186, \text { SPI } 205 \text {, SPI } 206 \text {, SPI } 207, \text { SPI } 285 \text {, SPI } 302 \text {, SPI } 325 \text {, SPI } 330, \text { SPI } \\
340, \text { SPI } 344 \text {, SPI } 357, \text { SPI } 369 \text {, SPI } 370, \text { SPI } 373 \text {, SPI } 443 \text {, SPI } 445 \text {, SPI } 525\end{array}$ & + & - & - & + \\
\hline SPI 323 & - & - & - & - \\
\hline
\end{tabular}

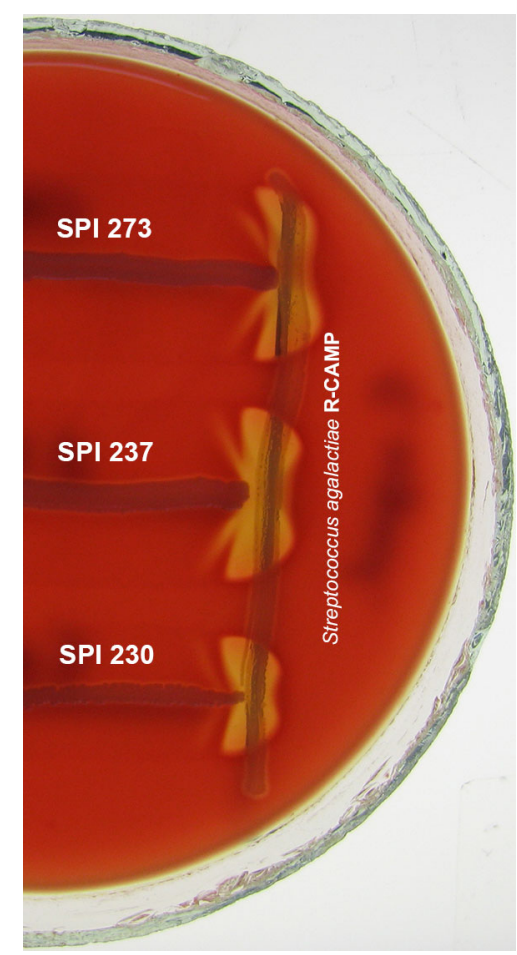

Fig. 1 Reverse CAMP test results of the selected S. pseudintermedius strains

cold effect, whereas the reverse CAMP test was negative (Fig. 1).

The presence of $h l b$ gene, in a PCR reaction with primers described in the literature [11], was confirmed only in 2 (4\%) S. pseudintermedius strains, whereas in the reaction with newly designed primers-in $50(98 \%)$ analysed $S$. pseudintermedius strains. The absence of $h l b$ gene was detected only in SPI 323 animal strain which was also negative in phenotypic $\beta$-haemolysin test.

The $h l b$ gene was detected in none of $S$. epidermidis control strains, nor in the $S$. aureus ATCC $^{\circledR} 25923$ and $S$. intermedius ATCC $^{\circledR} 29663$ reference strains. Results were negative in PCR reactions when both the described in the literature and the newly designed primers were used (Fig. 2).

The statistical analysis based on the $\chi^{2}$ test showed that the relationship between hot-cold effect and hlb gene presence in the PCR reaction with the newly designed primers was statistically significant $(P=0.00000)$.

\section{Discussion}

S. pseudintermedius strains are thought to constitutively produce $\beta$-haemolysin and rarely $\delta$-haemolysin [24]. Apart from classic phenotypic tests (hot-cold effect, reverse CAMP test), molecular analyses of $\beta$-haemolysin based on $h l b$ gene searching are also used $[6,9,11,21]$.

PCR reactions conducted in this study with primers described by Gharsa et al. [11] showed positive results only in $2(4 \%)$ out of 51 analysed S. pseudintermedius strains. This contradicts previous results showing common phenotypic demonstration of $\beta$-haemolysin presence, as well as previously described genotypic studies proving $h l b$ gene presence in strains able to produce $\beta$-haemolysin $[9,11$, 12].

On the basis of the S. pseudintermedius ED99 complete genome deposited in Genbank, we designed a new pair of primers for $h l b$ gene, which enable the analysis of $S$. pseudintermedius strains. PCR searching results completely confirmed phenotypic hot-cold test outcome, which proved to be more reliable than the reverse CAMP test.

The results described in this paper contest previous studies on the possibility of searching for $S$. pseudintermedius virulence genes using $h l b$ primers described for $S$. aureus [11], because they seem to be inadequate for $S$. pseudintermedius strains. This result also contests the credibility of previously published analyses of bacterial strains from SIG group. Primers proposed in this study for searching for $\beta$-haemolysin $h l b$ gene in $S$. pseudintermedius seem to be much more accurate in the detection of this virulence factor in bacterial strains of this species. 


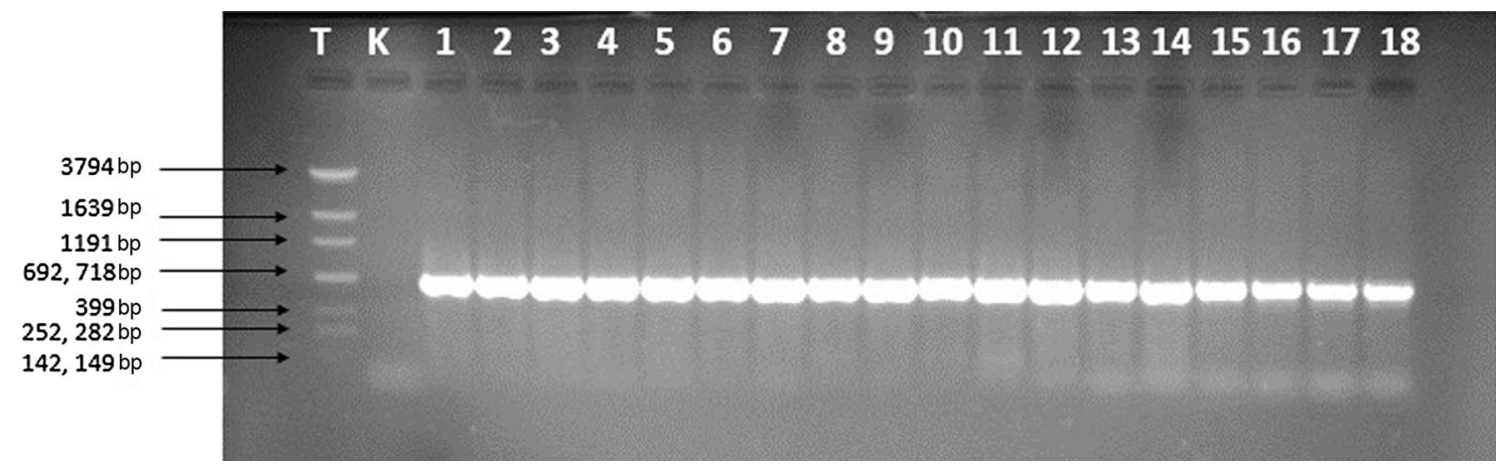

Fig. 2 Agarose gel electrophoresis of the selected PCR products after reaction with the newly designed primers (T-DNA Marker DraMix, Knegative control, 1-18—S. pseudintermedius strains SPI 150—SPI 391)

Preliminary studies on the newly designed primers showed also negative $h l b$ searching results for $S$. aureus and $S$. intermedius reference ATCC strains. This suggests that after further analysis, the fragment of $h l b$ gene amplified with primers described in this study might be included in the process of $S$. pseudintermedius strains identification. That would be extraordinarily desirable because of numerous difficulties in the differentiation among the species of the SIG group.

Funding This work was supported by the Medical University of Lodz (Grant No. 502-03/3-012-03/502-34-052).

\section{Compliance with Ethical standards}

Conflicts of interest None.

Open Access This article is distributed under the terms of the Creative Commons Attribution 4.0 International License (http://crea tivecommons.org/licenses/by/4.0/), which permits unrestricted use, distribution, and reproduction in any medium, provided you give appropriate credit to the original author(s) and the source, provide a link to the Creative Commons license, and indicate if changes were made.

\section{References}

1. Boost MV, So SYC, Perreten V (2011) Low rate of methicillinresistant coagulase-positive staphylococcal colonization of veterinary personnel in Hong Kong. Zoonoses Public Health 58:36-40

2. Chrobak D, Kizerwetter-Świda M, Rzewuska M, Moodley A, Guardabassi L, Binek M (2011) Molecular characterization of Staphylococcus pseudintermedius strains isolated from clinical samples of animal origin. Folia Microbiol 56:415-422

3. Chuang CY, Yang YL, Hsueh PR, Lee PI (2010) Catheter-related bacteremia caused by Staphylococcus pseudintermedius refractory to antibiotic-lock therapy in a hemophilic child with dog exposure. J Clin Microbiol 48:1497-1498

4. Decristophoris P, Fasola A, Benagli C, Tonolla M, Petrini O (2011) Identification of Staphylococcus intermedius Group by MALDI-TOF MS. Syst Appl Microbiol 34:45-51
5. Descloux S, Rossano A, Perreten V (2008) Characterization of new staphylococcal cassette chromosome mec (SCCmec) and topoisomerase genes in fluoroquinolone- and methicillin-resistant Staphylococcus pseudintermedius. J Clin Microbiol 46: 1818-1823

6. Devriese LA, Hermans K, Baele M, Haesebrouck F (2009) Staphylococcus pseudintermedius versus Staphylococcus intermedius. Vet Microbiol 133:206-207

7. Dziewanowska K, Edwards VM, Deringer JR, Bohach G, Guerra DJ (1996) Comparison of the beta-toxins from Staphylococcus aureus and Staphylococcus intermedius. Arch Biochem Biophys 335:102-108

8. Foster TJ (2009) Colonization and infection of the human host by staphylococci: adhesion, survival and immune evasion. Vet Dermatol 20:456-470

9. Futagawa-Saito K, Ba-Thein W, Sakurai N, Fukuyasu T (2006) Prevalence of virulence factors in Staphylococcus intermedius isolates from dogs and pigeons. BMC Vet Res 2:4

10. Gharsa H, Slama K, Gómez-Sanz E, Lozano C, Klibi N, Jouini A et al (2013) Antimicrobial resistance, virulence genes, and genetic lineages of Staphylococcus pseudintermedius in healthy dogs in Tunisia. Microb Ecol 66:363-368

11. Gharsa H, Slama KB, Gómez-Sanz E, Gómez P, Klibi N, Zarazaga $M$ et al (2015) Characterisation of nasal Staphylococcus delphini and Staphylococcus pseudintermedius isolates from healthy donkeys in Tunisia. Equine Vet J 47:463-466

12. Gómez-Sanz E, Torres C, Benito D, Lozano C, Zarazaga M (2013) Animal and human Staphylococcus aureus associated clonal lineages and high rate of Staphylococcus pseudintermedius novel lineages in Spanish kennel dogs: predominance of $S$. aureus ST398. Vet Microbiol 166:580-589

13. Hanselman BA, Kruth SA, Rousseau J, Weese JS (2009) Coagulase positive staphylococcal colonization of humans and their household pets. Can Vet J 50:954-958

14. Huseby MJ, Kruse AC, Digre J, Kohler PL, Vocke J, Mann EE et al (2010) Beta toxin catalyzes formation of nucleoprotein matrix in staphylococcal biofilms. Proc Natl Acad Sci USA 107:14407-14412

15. Julian T, Singh A, Rousseau J, Weese JS (2012) Methicillinresistant staphylococcal contamination of cellular phones of personnel in a veterinary teaching hospital. BMC Res Notes 5:193

16. Katayama Y, Baba T, Sekine M, Fukuda M, Hiramatsu K (2013) Beta-haemolysin promotes skin colonization by Staphylococcus aureus. J Bacteriol 195:1194-1203

17. Laurens C, Marouzé N, Jean-Pierre H (2012) Staphylococcus pseudintermedius and Pasteurella dagmatis associated in a case of community-acquired pneumonia. Méd Mal Infect 42:129-131 
18. Paul NC, Moodley A, Ghibaudo G, Guardabassi L (2011) Carriage of methicillin-resistant Staphylococcus pseudintermedius in small animal veterinarians: indirect evidence of zoonotic transmission. Zoonoses Public Health 58:533-539

19. Perreten V, Kadlec K, Schwarz S, Grönlund Andersson U, Finn M, Greko C et al (2010) Clonal spread of methicillin-resistant Staphylococcus pseudintermedius in Europe and North America: an international multicentre study. J Antimicrob Chemother 65:1145-1154

20. Riegel P, Jesel-Morel L, Laventie B, Boisset S, Vandenesch F, Prévost G (2011) Coagulase-positive Staphylococcus pseudintermedius from animals causing human endocarditis. Int $\mathrm{J}$ Med Microbiol 301:237-239

21. Różalska M, Szewczyk EM (2008) Staphylococcus cohnii haemolysins-isolation, purification and properties. Folia Microbiol 53:521-526

22. Sasaki T, Tsubakishita S, Tanaka Y, Sakusabe A, Ohtsuka M, Hirotaki S et al (2010) Multiplex-PCR method for species identification of coagulase-positive staphylococci. J Clin Microbiol 48:765-769

23. Savini V, Barbarini D, Polakowska K, Gherardi G, Białecka A, Kasprowicz A et al (2013) Methicillin-resistant Staphylococcus pseudintermedius infection in a bone marrow transplant recipient. J Clin Microbiol 51:1636-1638

24. Savini V, Kosecka M, Marrollo R, Carretto E, Międzobrodzki J (2013) CAMP test detected Staphylococcus delphini ATCC 49172 beta-haemolysin production. Pol J Microbiol 62:465-466

25. Singh A, Walker M, Rousseau J, Monteith GJ, Weese JS (2013) Methicillin-resistant staphylococcal contamination of clothing worn by personnel in a veterinary teaching hospital. Vet Surg 42:643-648

26. Smyth CJ, Möllby R, Wadström T (1975) Phenomenon of hotcold haemolysis: chelator-induced lysis of sphingomyelinasetreated erythrocytes. Infect Immun 12:1104-1111

27. Stegmann R, Burnens A, Maranta CA, Perreten V (2010) Human infection associated with methicillin-resistant Staphylococcus pseudintermedius ST71. J Antimicrob Chemother 65:2047-2048

28. Tajima A, Iwase T, Shinji H, Seki K, Mizunoe Y (2009) Inhibition of endothelial interleukin-8 production and neutrophil transmigration by Staphylococcus aureus beta-haemolysin. Infect Immun 77:327-334

29. Vos P, Garrity G, Jones D, Krieg N, Ludwig W, Rainey F et al (2009) Bergey's manual of systematic bacteriology, vol 3: the Firmicutes. Springer, New York

30. Walev I, Weller U, Strauch S, Foster T, Bhakdi S (1996) Selective killing of human monocytes and cytokine release provoked by sphingomyelinase (beta-toxin) of Staphylococcus aureus. Infect Immun 64:2974-2979

31. Wang N, Neilan AM, Klompas M (2013) Staphylococcus intermedius infections: case report and literature review. Infect Dis Rep 5:e3

32. Youn JH, Park YH, Hang'ombe B, Sugimoto C (2014) Prevalence and characterization of Staphylococcus aureus and Staphylococcus pseudintermedius isolated from companion animals and environment in the veterinary teaching hospital in Zambia, Africa. Comp Immunol Microbiol Infect Dis 37:123-130 